\title{
Behaviour Of Routing Protocols In Mobile AD HOC NETWORKS INVESTIGATED FOR EMERGENCY AND RESCUE SITUATION IN INDIA
}

\author{
S.Sivagurunathan ${ }^{1}$ and K.Prathapchandran ${ }^{2}$ \\ Department of Computer Science and Applications \\ Gandhigram Rural Institute-Deemed University, Gandhigram-624 302 \\ Tamilnadu, India
}

\begin{abstract}
Mobile Ad hoc Networks are open, shared, dynamic and self-organized networks. These distinct nature lead to efficient use in emergency and recue scenarios where the sharing of information is necessary. In order to share information within the network, a proper routing protocol is required to establish routes between nodes. This article discusses which of the routing protocols such as reactive or proactive has better performance in such scenario. In order to implement the test bed, we choose a real area in Uttarakhand state, India where the disaster occurred recently hence so many civilizations had vanished due to lack of communication and failure in recovery. Our aim is to choose an optimum routing protocol that is correct and used for efficient route establishment between nodes so that message could be delivered on time without loss and it will be implemented and used in future based on the model that we propose.
\end{abstract}

\section{KEYWORDS}

Mobile Ad Hoc Networks, Routing, Reactive Protocols, Proactive Protocols, Emergency and Rescue.

\section{INTRODUCTION}

Mobile Ad hoc network simply MANET is a collection of mobile nodes that are connected together over a structure less wireless medium and not to depend on any fixed infrastructure or central administration. Nodes are moving as they desire hence the topology of network may change rapidly. There are no routers for packet forwarding instead of that each node may also act as routers by the way each node expects cooperation from others and also have the nature of selforganization. In recent years, MANET has received tremendous attention because of the selfconfiguration and self-maintenance [1] capabilities. The advancement in the wireless communication plays a vital role in emergency and rescue operations because of improvement in end user hardware such as mobile devices, hand held devices, phones and more. In this changing weather conditions disaster become an unavoidable one. Since emergency differ from day to day operations to larger scale catastrophic events therefore an efficient communication is required to help people where the rescue is needed. In such situations the communication infrastructure is totally absent or damaged or previously deployed network may not be handling the traffic load [2]. The solution is MANET because it can be deployed and destroyed easily wherever it is required irrespective of time and situations time and works as a temporary network. It is composed of various elements denoted as scenario which consists of specific number of nodes,

DOI : 10.5121/ijwmn.2016.8103 
International Journal of Wireless \& Mobile Networks (IJWMN) Vol. 8, No. 1, February 2016

topology and also include the definition of mobility patterns such as speed, direction and pauses of the nodes [3]. In emergency and rescue scenario, the topology of the network is often changing due to the obstacles that may occur due to the unexpected events that affect the normal pathway of nodes. Therefore movement of routing algorithm is determined by the topology and the corresponding nodes should be moved depending on the obstacles [3].

Because of dynamic topology, routing is a considerable factor in MANET. It is the process of finding path from any source to any arbitrary destination. In this unstable environment routing of information from one place to another is a challenging task. We are in a situation that our information should reach the destination timely manner as well as without loss of any data. So this task is accomplished by routing protocols. The function of routing protocols is to maintain routing tables that store all available routing information and also dynamically maintain a router's routing table. To do this, routers must share information about the valid routes. This sharing is accomplished by the exchange of special packets that are called routing updates. The actual work of routing protocol is not to move data from one end to another end; it simply carries information about the best path from router to router [4]. Therefore routing is the process of directing packets from a source node to a destination node on a network. Getting packets to their next hop, a router needs to perform two basic activities: path determination and packet switching. Path determination is the process of choosing an optimal route from all the available routes typically from all the routing information stored in the respective routing tables. Packet switching involves changing a packet's physical destination address to that of the next hop. One can say that any routing algorithm works well if the following goals are satisfied such goals are, optimality; A routing protocol should be capable of choosing the optimal route or quickest route from all the several alternative routes. Flexibility; A protocol should have an ability to adapt to constantly changing network conditions. Rapid Convergence; if there is any change within the network, which change should propagate to all the routers within the minimum amount of time. The time it takes for all routers to be notified of the change is called convergence. Robustness; The protocols continue functioning even if any unpredictable and unusual change occurs. Simplicity; A protocol should be simple to be efficient.

The main objective of this paper is to determine which one of the routing protocols: reactive or proactive fit in emergency and rescue scenario for that we have chosen city called Baddrinath which is one of the notable places because of disasters in recent decades including floods and landslides in the Himalayan states of India and nearly 5,000 people must have been killed in the incident that occurred in July 2013. To implement our scenario we have chosen Network Simulator 3 (NS3) which is one of the upcoming and under development simulation tool for both wired and wireless networks and because of its simplicity, flexibility and modularity it gets more attention among the research communities.

\section{RELATED WORK}

As mentioned earlier, routing is the fundamental component in MANET due to the limited transmission range, unpredictable network topology and nodes are acting as routers because some nodes cannot contact others nodes directly. The following section discusses the impact of routing protocols in emergency and rescue scenario and also discuss the general routing protocols in such scenarios.

\subsection{General routing protocols for emergency and rescue scenarios}

In MANET classification of routing protocols are characterized based on geographical position, topology, grouping, geo cast and broad cast. Static routing [5] does not reflect any topology change that occurs in the network. But dynamic routing [6] automatically discovers routes and 
International Journal of Wireless \& Mobile Networks (IJWMN) Vol. 8, No. 1, February 2016

can react to network changes. Some protocols choose a single path from all available routes, that path information alone is stored in the routing table. In multipath, all available paths are stored in the routing table it causes higher throughput. It also supports multiplexing over multiple lines. A flat routing protocol [7] considers all routers as peers. In such routing all router would receive the same routing updates from all other routers. But in hierarchical routing protocol [8] there is some classification among routers. They may not receive same information; they only receive routing updates from other routers within their network also it keeps local traffic information. It reduces the bandwidth overhead required by the routing protocol and improves network performance. In distance vector routing [1], routing decisions are based on the distance of the remote destination in terms of the number of network layer hops that the packet will have to traverse. In link state routing [1], routing decisions based on messages received from other routers in the network that give information about the state of the links connected to them.

\subsection{Impact of routing protocols in emergency and rescue scenarios}

In order to enrich the routing, many protocols [9-12] have been proposed and compared by researchers and these algorithms are different in their route searching and establishment. The advantages of using MANET instead of fixed network for emergency and rescue scenario is proposed by [13]. More specifically the authors [14-16] and thus propose the behaviour of reactive protocols are working well in such scenario and also among the reactive routing protocols, AODV is provide better results in terms of routing metrics. Others have shown [17] [18]the performance of the routing protocols in emergency and rescue scenario and made a comparative analysis and conclude that among the reactive and proactive protocols, reactive is better suitable for such scenario. Knowing the significant of problems in emergency and rescue scenario, other authors [19] [20] also analyse the performance of the routing protocols in that scenario.

Among the protocols, we aim at reactive and proactive routing protocols. In reactive routing protocol [21] the routes are created only when it is needed. There is no need of periodic updates of routing tables compared with proactive or table driven protocol. In order to establish a route between source and the destination, it initiates a route discovery process that is used to send data to the destination. After the successful completion of route discovery process, the path is available to send data. In order to maintain consistency of routes between nodes route maintenance process is used. On Demand Routing Protocols are taken up for the discussion here. Some of the protocols are DSR [1], AODV [22] and TORA [1]. The main advantage of using this protocol in emergency and rescue is energy and bandwidth are saved because routes are created only when it is needed and there is no need of periodical updates so it improves communication with the affected area and generally devices are resource constrained so if using this protocols it enriches the lifetime of involved devices.

On the other hand proactive protocols maintain all the routing information in routing tables of nodes even if they are not required. Routes are updated periodically by exchanging control information between nodes so as to maintain consistency in the network. The main reason for periodic updates is to pre-calculate all possible paths. Hence whenever changes occur in the network, in order the keep the routing tables get refreshed, periodic updates are important. Therefore, in such scenario to rescue people who are in affected area is achieved with the help of continuous assessment of route updates among the nodes. Even if it has advantages, too much of updates lead to overall network performance is in question. Moreover it performs well at static network and not in dynamic networks because of the scalability issues [3]. The well-known proactive routing protocols are DSDV [1] WPR [23] and OLSR [24]. 
International Journal of Wireless \& Mobile Networks (IJWMN) Vol. 8, No. 1, February 2016

As shown in previous discussion, both proactive and reactive protocols have their own advantages and disadvantages. However many research papers [25-27] have shown reactive protocols perform well compared with proactive protocols. In this paper we investigate reactive and proactive protocols namely AODV and DSDV by means of taking the following considerations. For any mobile communication utilization of battery power is significant because of power constrain and minimizing the control overhead is also important because it affects the overall network performance therefore in connection with these requirements reactive protocols are considered for our analysis because in AODV, routes are updated only when it is required by the way to minimize the power consumption and control overhead and also in [14-16] authors shown the better performance of AODV. Quality of service is one of the considerable factors in this uncertain environment because we could not predict the topology and link break between the mobile nodes. In DSDV, routing information are updated to all available destination therefore even if link breakage and topology change, every node can get the accurate routing information so that quality of service is increased and also end to end delay is minimized. In addition author has [28] shown the better performance of DSDV.

\section{Proposed Scenario: Case Study}

The motivation for the work is formed after the flooding and landslides which occurred in one of the Himalayan states of India called Uttarakhand and it also called as lands of gods by Indian. In recent decades, it is notable for an excess of natural disasters including flooding and landslides in almost every monsoon season. In the year 2013, nearly 5000 people were killed including pilgrims and tourists due to heavy rainfall and landsides in the month of June [29]. Especially the districts Rudraprayag, Uttarkashi and Chamoli get damaged a lot. For our study, we focus the holy town called Badrinath which is located in the district of chamoli and the area surrounded by about $3 \mathrm{~km}^{2}$ [30][31]. The Figure .1 shows the view of Baddrinath temple after flood hit in the year 2013 .

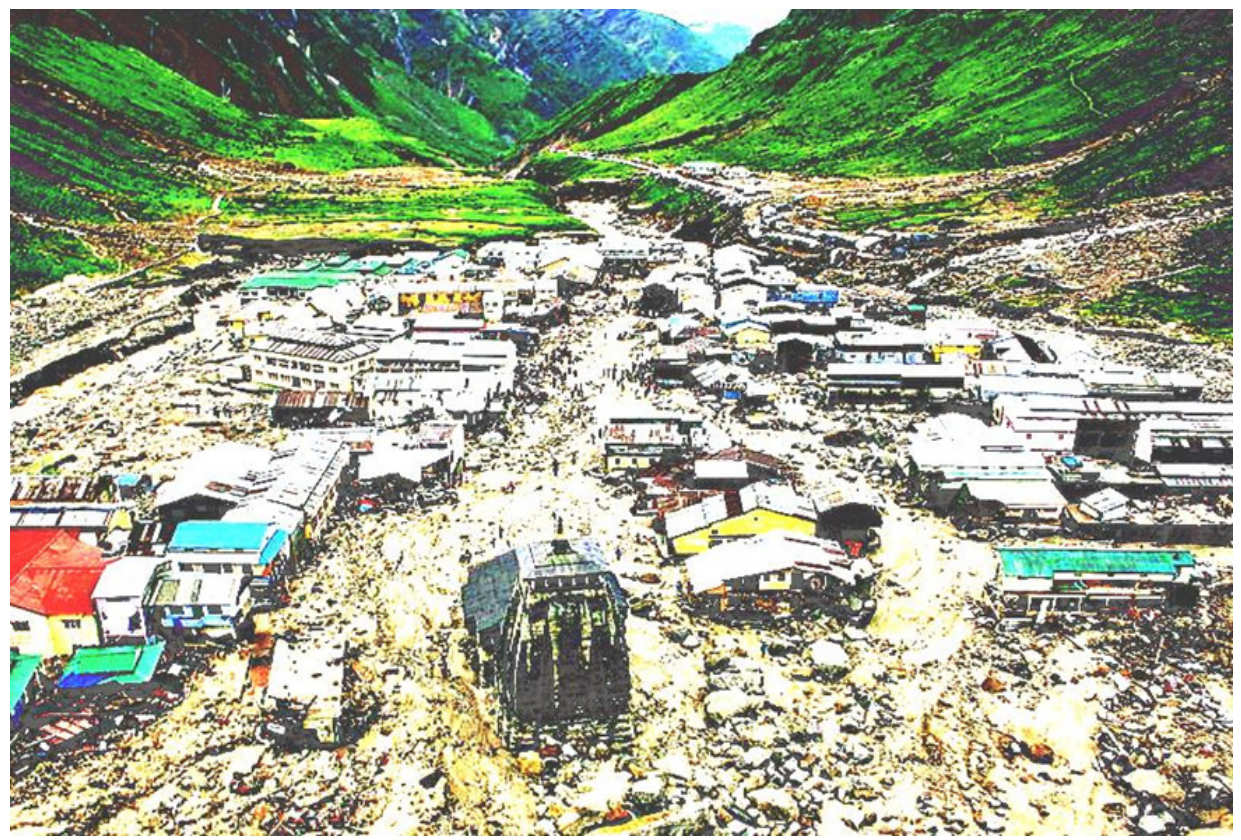

Figure 1. An outlined view of Badrinath town after the flood hit in the year 2013 
International Journal of Wireless \& Mobile Networks (IJWMN) Vol. 8, No. 1, February 2016

The objective of the paper is to study the impact of routing protocols in such emergency scenario through simulation by the way we can choose the feasible routing protocol that is suitable for the real time scenario. At the time of emergency, though public safety organizations and law enforcement agencies are present, due to shortage of networking communication infrastructure, lack of experience in rescue operations, complex environment and the unawareness of context conditions all these factors make trouble in rescue operation. Moreover the success of rescue operation depends on the following factors: responders tracking, in field injured person triaging and physical environment monitoring [3] Therefore an optimum routing strategy is required to spread the communication throughout the affected area as soon as possible by the way it would rescue people.

\section{A PROTOTYPE OF AODV AND DSDV ROUTING IN THE BADDRINATH TOWN}

In this section we describe how the AODV and DSDV routing strategy can be executed in such a scenario. The handheld mobile devices can be utilized in rescue operation and these devices are carried by rescuers named as nodes. Each node is configured with IEEE 802.11b technologies hence power consumption is $\sim 30 \mathrm{~mW}$ and it can be covered up to $500 \mathrm{~m}$ and frequency is $2.4 \mathrm{GHz}$. If we study AODV routing is involved in the proposed scenario, as discussed earlier routes are discovered only on demand basis so during the emergency if any evacuation point is received by a node. Prior each node is maintaining a routing table consists of destination address denoting the evacuation point where actually rescue is needed, next hop address which denotes the intermediate rescuer's node and destination sequence numbers which is used to avoid travel on the same evacuation point again termed as routing loop. In order to perform rescue operation with that point first check their routing table whether a route to the denoted evacuation point is available. If it so, it utilizes that route otherwise it initiate a new route discovery process in order to reach the target point. Once the target point is identified, forward paths set and give response to the node by a target point's node. By the way routing can be achieved in AODV routing scenario. Here routing information advertisement follows unicast or multicast or broadcast or the combination of the above. The Figure. 2 denote the model of AODV routing in Baddrinath scenario.

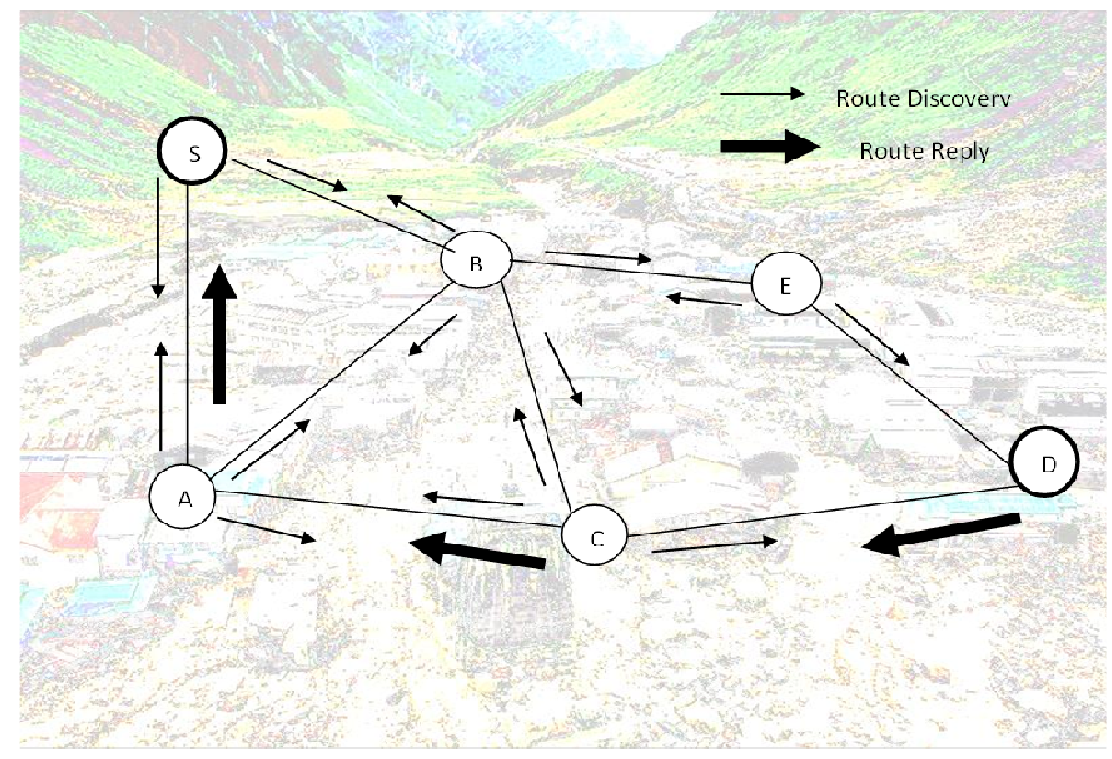

Figure 2. A prototype model of AODV Routing in the town of Badrinath 


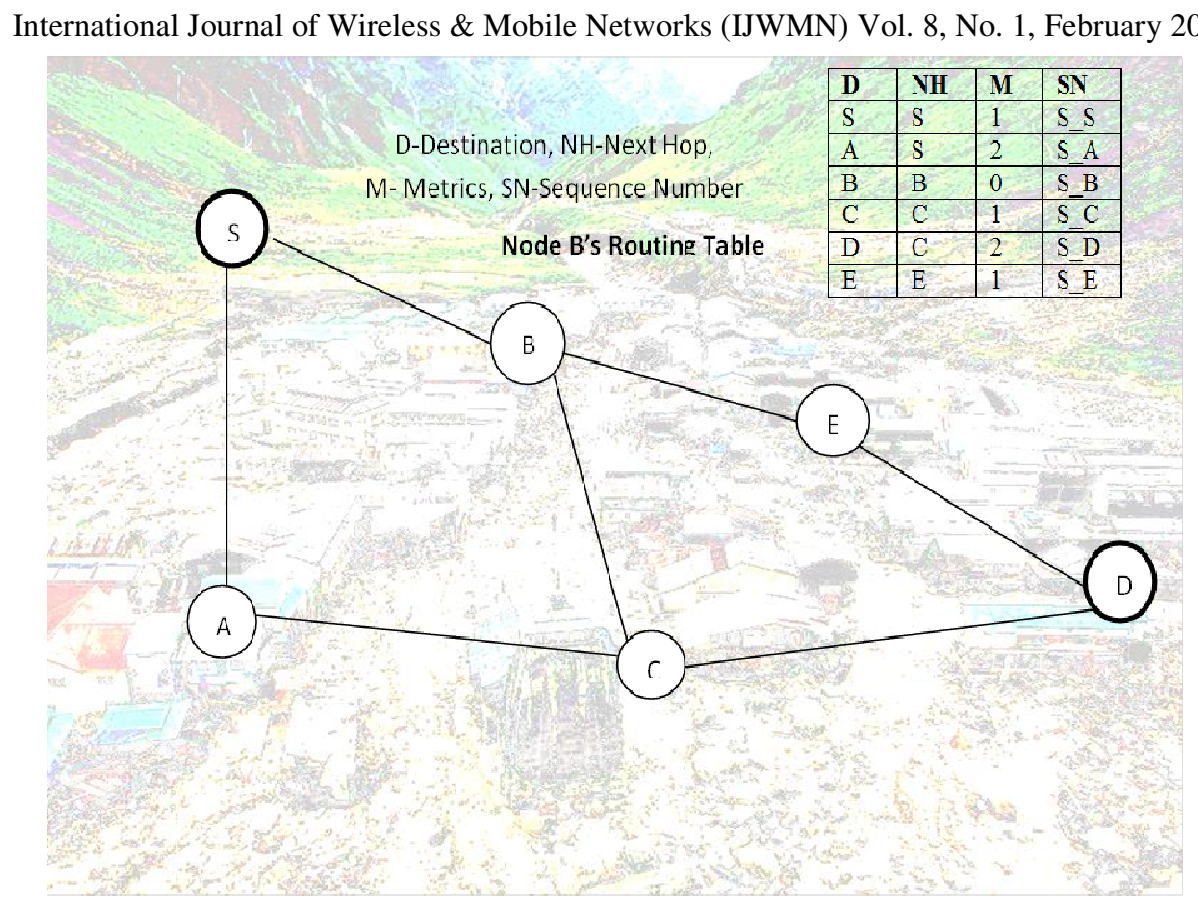

Figure 3. A prototype model of DSDV Routing in the town of Badrinath

On the other hand, if we study DSDV routing in the proposed scenario, as discussed earlier all the nodes are maintaining routing information it their routing table so every node maintains the evacuation points in its table. During emergency whenever changes occurs in the rescue operation among the rescuers those information also updated immediately. Here each rescuer advertises its routing information to its neighbors and also responsible for forwarding the rescue information upon request. Here the routing information is advertised either multicast or broadcast. The Figure. 3 denote the model of DSDV routing in Baddrinath scenario.

Table 1. Routing tables of both AODV and DSDV

\begin{tabular}{|l|l|}
\hline \multicolumn{2}{|c|}{ Routing } \\
\hline AODV & DSDV \\
\hline Destination Address & Destination Address \\
\hline Next hop IP Address & No. of hops to reach the destination \\
\hline Destination Sequence Number & Destination Sequence Number \\
\cline { 1 - 1 } $\begin{array}{l}\text { Precursor Nodes ( Purpose of Route } \\
\text { Maintenance) }\end{array}$ & \\
\hline
\end{tabular}

Based on the discussion above AODV shows better performance in such a scenario because there is no overhead of periodic updates henceforth the energy is retained. Therefore rescues operations can be performed as long as energy is with nodes. Whereas in DSDV due to the update process nodes can consume their energy as well as delay in retrieval of information so that finding of affected area dramatically increases. The Table. 1 shows the routing table entries of both AODV and DSDV routing protocols. 
International Journal of Wireless \& Mobile Networks (IJWMN) Vol. 8, No. 1, February 2016

\section{DESIGN GOALS OF ROUTING PROTOCOLS}

Any routing protocols should have the following design goals.

\subsection{Optimality}

A routing protocol should be capable of choosing the optimal route or quickest route from all the several alternative routes.

\subsection{Flexibility}

A protocol should have an ability to adapt to constantly changing network conditions.

\subsection{Rapid Convergence}

If any change within the network, that change should propagate to all the routers within the minimum amount of time. The time it takes for all routers to be notified of the change is called convergence.

\subsection{Robustness}

The protocols continue functioning even if any unpredictable and unusual change occurs.

\subsection{Simplicity}

A protocol should be simple to be efficient.

\section{FACTORS THAT INFLUENCE ROUTING PROCESS DURING EMERGENCY SITUATIONS}

We are in situation to consider some important aspects because such aspects are affecting the routing process indirectly and make influence on routing process during the rescue operations. Such factors are,

\subsection{Connectivity}

Engage in the recovery process, connectivity among the rescuers is needed so that emergency related information could reach on time by the way quality of rescue operation can be achieved.

\subsection{Mobility}

Rescuers are often choked in traffic during the recovery process therefore the underlying structure of the network is changed so that utilizing the proper mobility among the nodes is important.

\subsection{Energy consumption}

It is also one of the considerable factors because routing process consumes battery power because nodes are in situation to involve in feasible path finding process, forwarding process and optimal route calculation therefore efficient usage of energy is important. 
International Journal of Wireless \& Mobile Networks (IJWMN) Vol. 8, No. 1, February 2016

\subsection{Security}

It also influences on routing because of the open and distributed recovery process in emergency, there is a possibility of attack rescue operations.

\section{Simulation Study for the Proposed Scenario}

To perform comparative analysis, it is necessary to define the simulation parameters that correspond to the proposed scenario. Before that, the proposed scenario is implemented in Network Simulator 3 (NS3). It is a discrete event simulator tool targeted for researchers and academicians and at present is getting more attention among the researchers because of its flexibility and modularity compared to other simulation tools. Our study area is surrounded by $1 \mathrm{~km} \mathrm{X} 2 \mathrm{~km}$ based on this we set $500 \mathrm{~m} \times 1000 \mathrm{~m}$ for simulation. Next, movement of rescuers in rescue operation is one of the important factors therefore we set the node speed $2 \mathrm{~m} / \mathrm{s}$ because a normal human walking speed from 0 to $2.5 \mathrm{~m} / \mathrm{s}$ by the we utilize the Random Waypoint mobility model [32]. Furthermore the density of nodes is derived from the population of the affected area from low to high so we make use of 10, 30, 60 and 100 nodes for our study. Less than half of the connections among the density of the nodes we make. The following Table.2 illustrates the simulation parameters that we assume for the proposed scenario.

Table 2. Simulation parameters

\begin{tabular}{|l|l|l|}
\hline System Parameters & Reflection in Real Scenario & Values Utilized \\
\hline Number of nodes & Rescuers involved in rescue operation & $10,30,60,100$ \\
\hline Mobility Model & $\begin{array}{l}\text { Rescuers can move along a zigzag } \\
\text { line from one rescue point to another } \\
\text { by the way rescue points are } \\
\text { uniformly distributed over the given } \\
\text { affected area }\end{array}$ & $\begin{array}{l}\text { RandomWaypoint } \\
\text { MobilityModel }\end{array}$ \\
\hline Simulation Time & $\begin{array}{l}\text { Denoting the overall time of rescue } \\
\text { operation }\end{array}$ & $50 \mathrm{Sec}$ \\
\hline Simulation Size & $\begin{array}{l}\text { Denoting the covering area for rescue } \\
\text { operation }\end{array}$ & $1000 \mathrm{~m} \times$ 2000m \\
\hline Protocols & $\begin{array}{l}\text { Used for exchange emergency related } \\
\text { information }\end{array}$ & AODV, DSDV \\
\hline Data Rate & $\begin{array}{l}\text { Denoting amount of digital data } \\
\text { moved from one evacuation point to } \\
\text { another }\end{array}$ & $3072 \mathrm{bps}$ \\
\hline Packet Size & $\begin{array}{l}\text { Denoting the unit of data that is } \\
\text { originated from one evacuation point } \\
\text { to another }\end{array}$ & $64 \mathrm{byte}$ \\
\hline Wi-Fi ad hoc & $\begin{array}{l}\text { Rescuer's nodes are in ad hoc mode } \\
\text { so that easy deploy at anywhere and } \\
\text { need of centralized structure }\end{array}$ & $802.11 \mathrm{~b}$ \\
\hline Traffic & $\begin{array}{l}\text { Type of data that is transmitted } \\
\text { during the rescue operation. }\end{array}$ & UDP \\
\hline Node Speed & $\begin{array}{l}\text { Denoting the rescuers walking speed } \\
\text { There is no stop time for rescuers } \\
\text { during the operation }\end{array}$ & $20 \mathrm{~m} / \mathrm{s}$ \\
\hline Node Pause & $\begin{array}{l}\text { Denoting the actual amount of } \\
\text { transmit power of radio frequency } \\
\text { produced by the rescuer's node }\end{array}$ & $7.5 \mathrm{dbm}$ \\
\hline Transmission Range & \\
\hline
\end{tabular}


International Journal of Wireless \& Mobile Networks (IJWMN) Vol. 8, No. 1, February 2016

\subsection{Performance analysis of Simulation results}

In this section performance of AODV and DSDV are analyzed based on the metrics called delay, throughput and packet delivery ratio. These metrics are very significant because they assess the overall network performance for any application which is going to be deployed before by the way with the support of routing protocols we apply these metrics and measure to analyze which protocol is suitable for emergency and rescues operation.

\subsubsection{Delay}

It is one of the considerable metrics and refers average time taken by a packet to reach the destination from the source and generally it is calculated by subtraction of time at which packet is sent from and time at which packet is received. Commonly, delay should be low in communication for any kind of application.

In emergency and recuse operations, receiving of information as early as possible is important to rescue people who are in trouble and too much of delay affect the rescue operation. As shown in Figure .4 the delay of DSDV is very high and the number of nodes increases, delay also greatly increased. Whereas in AODV, delay is getting low even if the number of nodes increased. The Table. 3 show the delay data that we calculated during the simulation.

Table 3. AODV and DSDV delay analysis

\begin{tabular}{lcccc}
\hline \multicolumn{5}{c}{ Number of Nodes } \\
\hline \multicolumn{1}{c}{ Protocols } & 10 & 30 & 60 & 100 \\
\hline AODV & 16.6179 & 18.1233 & 14.0539 & 11.3224 \\
DSDV & 41.5104 & 43.6283 & 44.2103 & 44.4388 \\
\hline
\end{tabular}

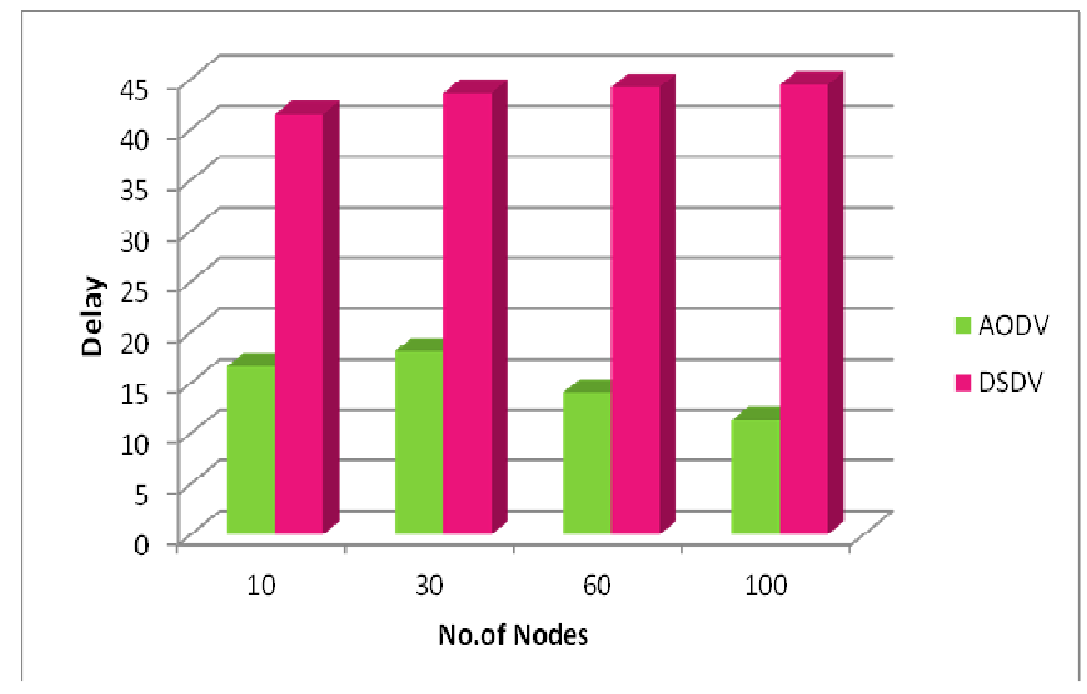

Figure 4. Delay analysis of AODV and DSDV over the number of nodes 
International Journal of Wireless \& Mobile Networks (IJWMN) Vol. 8, No. 1, February 2016

\subsubsection{Packet delivery ratio}

This metrics shows the ratio of the number of packets delivered to particular destination and it is measured by actual number of packets received divided by actual number of packets sent by source nodes. This metrics analyze whether the transmitted data properly reaches the destination or not. Based on the observations earlier, packet delivery ratio should be high for efficient communication.

In emergency and rescue operation, transmitted data should reach the destination as it is sent without any loss. It helps the rescuers to get the proper information from other rescuers by the way operations can be carried out efficiently. As shown in Figure.5 packet delivery ratio of AODV is getting high even though number of nodes has increased. Whereas in DSDV, it is low and when number of nodes increases, it slightly increased but not high when compare with AODV. Table shows the data of packet delivery ratio that we calculated during the simulation. Table. 4 shows the data of packet delivery ratio that we calculated during the simulation.

Table 4. AODV and DSDV Packet Delivery Ratio analysis

\begin{tabular}{lrrrr}
\hline \multicolumn{5}{c}{ Number of Nodes } \\
\hline \multicolumn{1}{c}{ Protocols } & 10 & 30 & \multicolumn{1}{c}{60} & \multicolumn{1}{c}{100} \\
\hline AODV & 30.13 & 515.76 & 1816.26 & 2077.25 \\
DSDV & 10.54 & 33.17 & 61.28 & 102.12 \\
\hline
\end{tabular}

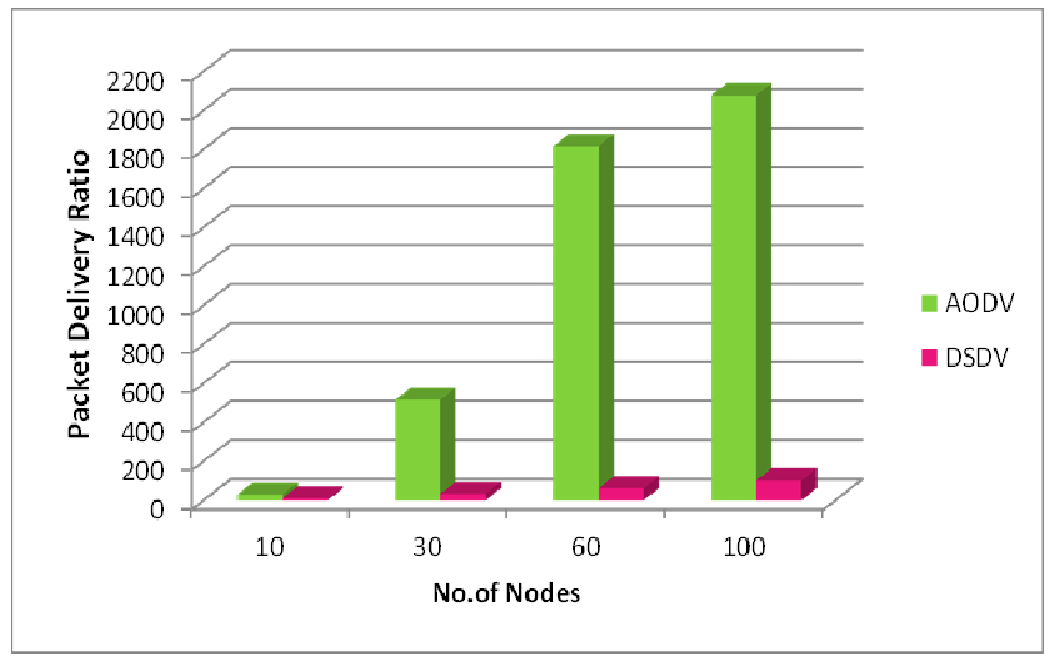

Figure 5. Packet Delivery Ratio analysis of AODV and DSDV over the number of nodes

\subsubsection{Throughput}

It is also one of the considerable metrics because it shows the overall performance of network over a given period of time and it is calculated by sum of successful delivered packet divided by total simulation duration alternatively we can also calculate by subtracting the total amount of data received by a destination from the sender to the time it takes for the destination to get the last packets. Based on the earlier observation, throughput should be high. 
International Journal of Wireless \& Mobile Networks (IJWMN) Vol. 8, No. 1, February 2016

In emergency and rescue operation, if throughput is high, communication between the rescuers would be greatly high hence we can assume rescue operations are going well. As shown the Figure. 6 throughput of AODV is high compared with DSDV. Though number of nodes is increased, throughput of AODV is linearly increased. Table.5 shows the data of throughput calculated during the simulation.

Table 5. AODV and DSDV Throughput analysis

\begin{tabular}{lllll}
\hline \multicolumn{5}{c}{ Number of Nodes } \\
\multicolumn{1}{c}{ Protocols } & \multicolumn{1}{c}{10} & \multicolumn{1}{c}{30} & \multicolumn{1}{c}{60} & 100 \\
\hline AODV & 626.43 & 3610.91 & 9636.77 & 7758.61 \\
DSDV & 6.38 & 47.63 & 168.11 & 419.64 \\
& & & & \\
\hline
\end{tabular}

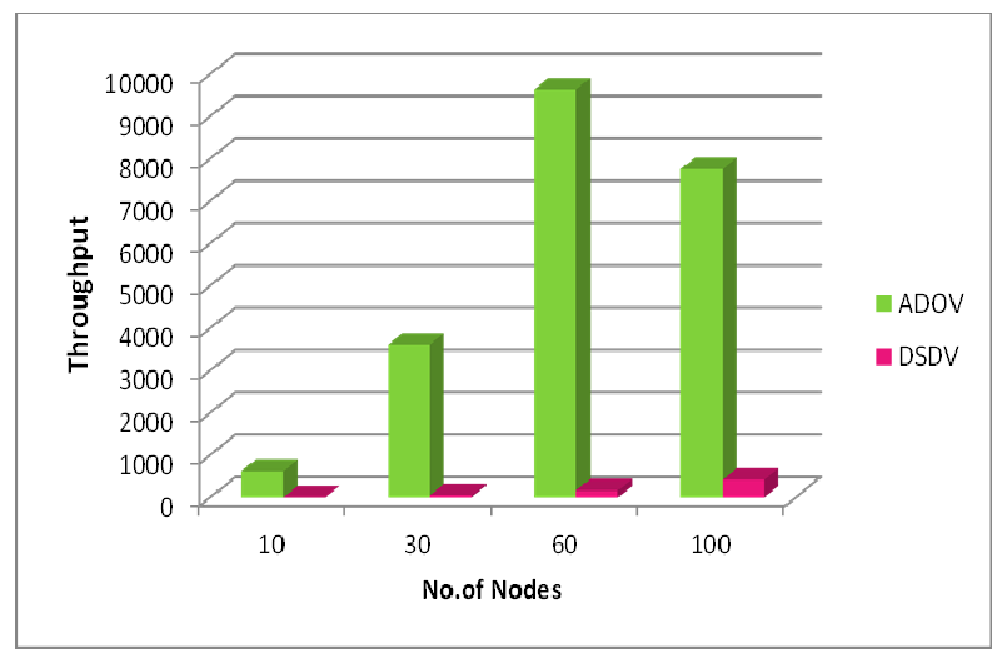

Figure 6. Throughput analysis of AODV and DSDV over the number of nodes

Overall Performance of AODV and DSDV - as shown in Figure.7 the overall performance of AODV does not degrade though number of nodes is increased in terms of delay, throughput and packet delivery ratio. Whereas in DSDV as shown in Figure.8 the performance of DSDV is low compare with AODV. Table. 6 and Table.7 show the overall performance of both AODV and DSDV and Table.8 overall performance comparison of both AODV and DSDV in terms of performance metrics.

Table 6. Overall Performance of AODV

\begin{tabular}{lllcc}
\hline \multicolumn{5}{c}{ Number of Nodes } \\
\multicolumn{1}{c}{ AODV } & 10 & \multicolumn{1}{c}{30} & 60 & 100 \\
\hline Delay & 16.6179 & 18.1233 & 14.0539 & 11.3224 \\
Packet Delivery & 30.13 & 515.76 & 1816.26 & 2077.25 \\
Ratio & 626.43 & 3610.91 & 9636.77 & 7758.61 \\
Throughput & & & & \\
\hline
\end{tabular}


International Journal of Wireless \& Mobile Networks (IJWMN) Vol. 8, No. 1, February 2016

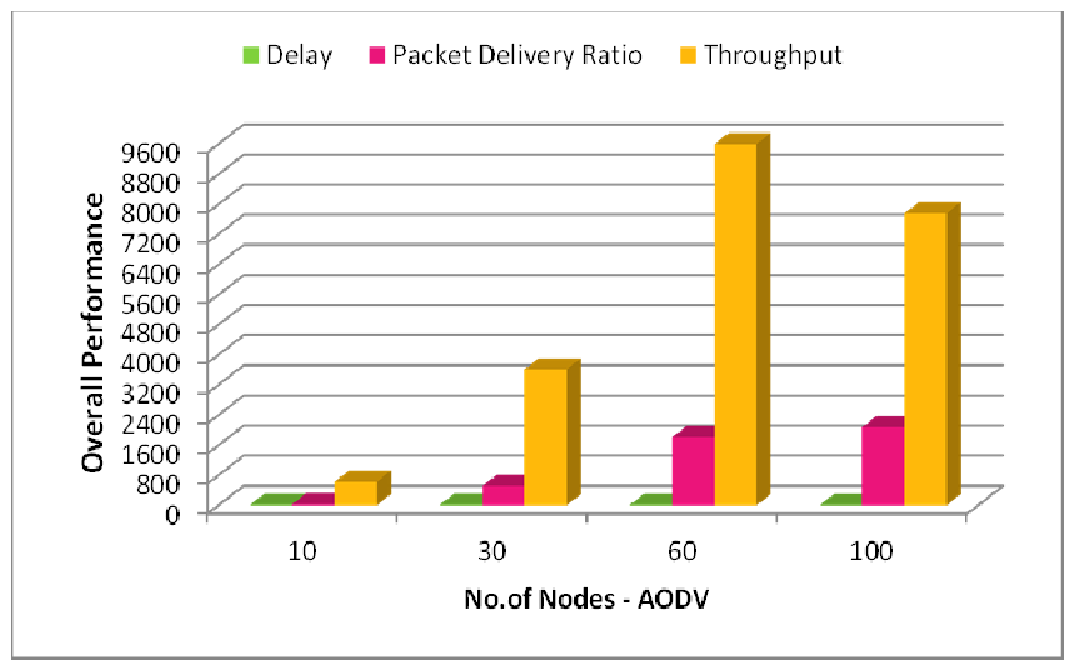

Figure 7. Overall Performance of AODV over the number of nodes

Table 7. Overall Performance of DSDV

\begin{tabular}{lcccc}
\hline \multicolumn{5}{c}{ Number of Nodes } \\
\hline \multicolumn{1}{c}{ DSDV } & 10 & 30 & 60 & 100 \\
\hline $\begin{array}{l}\text { Delay } \\
\text { Packet Delivery }\end{array}$ & 41.5104 & 43.6283 & 44.2103 & 44.4388 \\
Ratio & & & & \\
Throughput & 10.54 & 33.17 & 61.28 & 102.12 \\
\hline
\end{tabular}

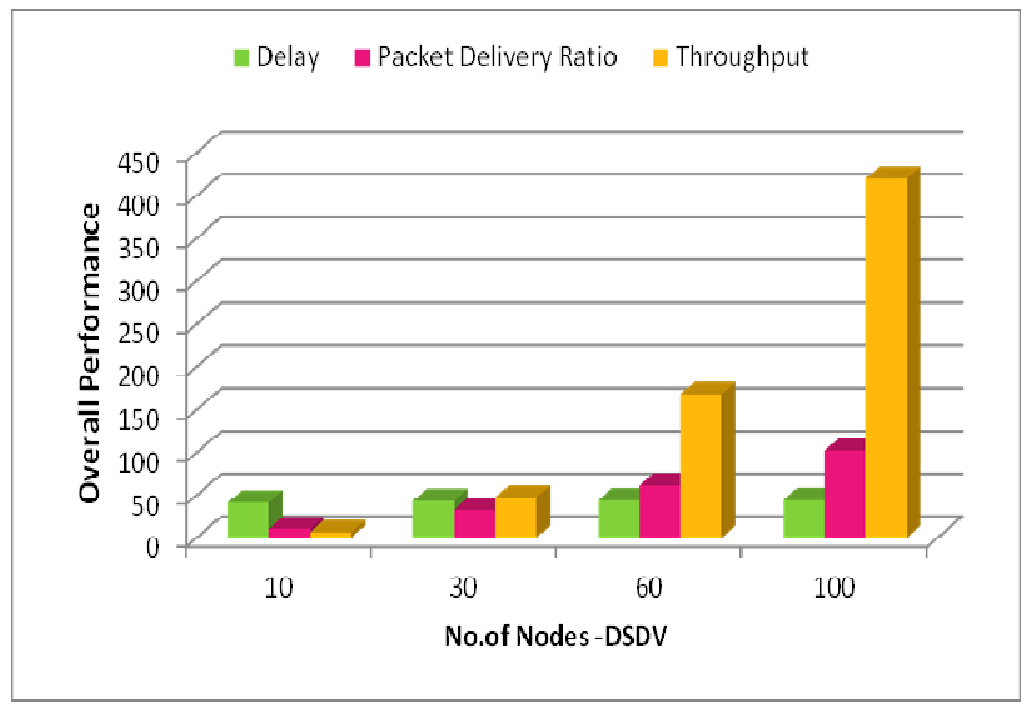

Figure 8. Overall Performance of DSDV over the number of nodes 
International Journal of Wireless \& Mobile Networks (IJWMN) Vol. 8, No. 1, February 2016

Table 8. Performance Comparison of AODV and DSDV

\begin{tabular}{lcc}
\hline $\begin{array}{l}\text { Performance } \\
\text { Parameters }\end{array}$ & AODV & DSDV \\
\hline Delay & Low & High \\
Packet Delivery Ratio & High & Low \\
Throughput & High & Low \\
Memory & Low & High \\
Routing Overhead & Low & High \\
Periodic Updates & Low & High \\
Power Consumption & Low & High \\
\hline
\end{tabular}

\section{Conclusions}

During the past decade, environment conditions are getting changed hence natural disasters such as flooding, earthquake and landslides can be expected. Emergency and relief operation is required to cope up with such situation and today's network communication play a vital role in rescue operation. In the advancement of communication technology, though traditional network infrastructure exists, they could not support such environment due to centralized, difficulty in deployment, lack of self-configuration and changing network structure so alternative solution is Mobile Ad hoc networks because of its significant characteristics. In addition to, routing algorithm that is used for traditional is not suitable for such scenario so finding of new algorithms are necessary; that is provided by MANET for efficient communication in such scenario.

The simulation study evaluates the performance of both AODV and DSDV. Based the observation we made AODV is suitable for such scenario because packet delay is relatively low compared to DSDV. Though number of nodes is increased, it does not reflect any change in delay. In packet delivery ratio, AODV is getting better result compared to DSDV and throughput also high for AODV compared to DSDV. Finally, the research work recommends the use of AODV protocol for such emergency and rescue scenario due to its performance in terms of throughput, Packet Delivery Ratio and End to End Delay.

\section{ACKNOWLEDGEMENT}

This research work is supported by University Grant Commission, India, through a Major Research Project, Grant (UGC.F.No: 42-128/2013 (SR).

\section{REFERENCES}

[1] Charles E.Perkins. (2008). Ad Hoc Networking. Addison-Wesley

[2] David Abusch-Magder., Peter Bosch., Thierry E. Klein., Paul A. Polakos., Louis G. Samuel., \& Harish Viswanathan. (2007). NOW: A Network on Wheels for Emergency Response and Disaster Recovery Operations. Bell Labs Technical Journal, 11(4), 113-133.

[3] Liniana Enciso Quispe., \& Luis Mengual Galan (in press). (2013). Behavior of Ad Hoc routing protocols, analyzed for emergency. Expert System with Applications.

[4] Imrich Chlamtac., Marco Conti., \& Jennifer J.-N. Liu. (2003). Mobile ad hoc networking: imperatives and challenges. Ad Hoc Networks, 1, 13-64.

[5] Inbeel,A.A.S., Sigiuk,H.I., \& Alhnsh,A.A . (2012). Simulation based evaluation of MANET routing protocols for static WSN. Second International Conference on Innovative Computing Technologies, 63-68.IEEE 
International Journal of Wireless \& Mobile Networks (IJWMN) Vol. 8, No. 1, February 2016

[6] Parma Nand., \& S. C. Sharma. (2012). Comparison of Routing Protocols for MANET and Performance Analysis of DSR Protocol Advances in Computing. Communication and Control Communications in Computer and Information Science, 125,406-412.

[7] Ghulam Yasin., Syed Fakhar Abbas., \& S R Chaudhry. (2013).MANET Routing Protocols for RealTime Multimedia Applications. WSEAS Transactions on Communications, E-ISSN: 2224-2864 386, 8(12), 386-395.

[8] Chaba, Y., Singh, Y., \& Joon, M. (2009). Performance evaluation and analysis of cluster based routing protocols in MANETS. 64-66.

[9] Charles E. Perkins., Elizabeth M. Royer., Samir R. Das., \& Mahesh K. Marina. (2001). Performance Comparison of Two On-Demand Routing Protocols for Ad Hoc Networks. IEEE Personal Communications, 16-28.

[10] Mehran Abolhasana., Tadeusz Wysockia., \& Eryk Dutkiewiczb. (2004). A Review of Routing Protocols for Mobile Ad hoc Networks. Ad Hoc Networks, 2(1), 1-22.

[11] Ha Duyen Trung., Watit Benjapolakul., \& Phan Minh Duc. (2007). Performance Evaluation and Comparison of Different Ad Hoc Routing Protocol. Computer Communications, 30(11-12), 24782496.

[12] A.A.A. Radwan., T.M. Mahmoud. , \& E.H. Houssein. (2011). Evaluation comparison of some ad hoc networks routing protocols. Egyptian Informatics Journal, 12, 95-106.

[13] D. G. Reina., S. L. Toral., N. Bessis., F. Barrero., \& E Asimakopoulou. (2013). An Evolutionary Computation Approach for Optimizing Connectivity in Disaster Response Scenarios. Applied Soft Computing, 13, 833-845.

[14] Reina, D. G., Toral, S., Barrero, F., Bessis, N., \& Asimakopoulou, E. (2011). Evaluation of ad hoc networks in disaster scenarios. In 2011 third international conference on intelligent networking and collaborative systems , 759-764.

[15] Reina, D., Marn, S. T., Bessis, N., Barrero, F., \& Asimakopoulou, E. (2013). An Evolutionary computation approach for optimizing connectivity in disaster Response scenarios. Applied Soft Computing, 13(2), 833-845.

[16] Reina, D., Toral, S., Barrero, F., Bessis, N., \& Asimakopoulou, E. (2012). Modeling and Assessing ad hoc networks in disaster scenarios. Journal of Ambient Intelligence and Humanized Computing, 1-9.

[17] Sadasivam, K., Changrani, V., \& Yang, T. A. (2005). Scenario based performance evaluation of secure routing in MANETS. In L. T. Yang, H. R. Arabnia, \& L.-C. Wang(Eds.), ICWN, 24-32, CSREA Press.

[18] Jadeja, N., \& Patel, R. (2013). Performance evaluation of AODV, DSDV and DSR routing protocols using ns-2 simulator. Performance Evaluation, 3(2), 825-1830.

[19] Fujiwara, T., \& Watanabe, T. (2005). An ad hoc networking scheme in hybrid Networks for emergency communications. Ad Hoc Networks, 3(5), 607-620.

[20] Chen, A. Y., Pea-Mora, F., Plans, A. P., Mehta, S. J., \& Aziz, Z. (2012). Supporting urban search and rescue with digital assessments of structures and requests of response resources. Advanced Engineering Informatics. SI: Modern Concurrent Engineering, 26(4), 833-845.

[21] Sivagurunathan S., \& Prathapchandran K. (2013). A Comparative Study on Reactive or On Demand Routing Protocols in Mobile Ad Hoc Networks. International Journal of Computer Applications (IJCA), ISSN: 0975-8887.

[22] Samir R. Das., Charles E. Perkins., Elizabeth M. Royer., \& Mahesh K. Marina. (2001). Performance Comparison of Two On-demand Routing Protocols for Ad hoc Networks. IEEE Personal Communications Magazine special issue on Ad hoc Networking, 16-28.

[23] Baltzer Journals., Shree Murthy and J.J., \& Garcia-Luna-Aceves.(1995). An Efficient Routing Protocol for Wireless Networks, Retrieved on February, 5, 2015.

[24] P.Jacquet, P.Muhletthaler., A.Laouiti, A.Qayyum., \& L.Viennot. Optimized link state routing protocol for ad hoc networks, Retrieved on February, 5, 2015.

[25] A.P.Janani., M.Sakthivel., \& K.Baskaran.(2013). A Competitive Performance analysis of Reactive and Proactive Routing Protocols of MANET under Short time Communication Scenario. International Journal of Wireless and Mobile Computing, 6(3), 253-260

[26] Vikas Singla., Parveen Kakkar., \& Dinesh Kumar. (2011). Study and Investigation of Performance of Reactive and Proactive Protocols of MANET on the Basis of CBR and TCP Traffic Pattern. Networking and communication engineering, 12. 
International Journal of Wireless \& Mobile Networks (IJWMN) Vol. 8, No. 1, February 2016

[27] Ahmed A. Radwan., Tarek M. Mahmoud., \& Essam H. Houssein. (2011). Performance Measurement of Some Mobile Ad Hoc Network Routing Protocols. IJCSI International Journal of Computer Science Issues, 8(1), 107-112.

[28] Kumawat, R., \& Somani, V. (2011). Article: Comparative analysis of DSDV and OLSR Routing protocols in MANET at different traffic load. In IJCA Proceedings on International Conference on Computer Communication and Networks CSI-COMNET- New York, USA: Foundation of Computer Science

[29] Uttarakhand floods a man-made disaster, The Hindu http://www.thehindu.com/todays-paper/tpnational/uttarakhand-floods-a-manmade-disaster/article4835692.ece, retrieved on January 22, 2015.

[30] http://en.wikipedia.org/wiki/Uttarakhand, Retrieved on January 22, 2015.

[31] Report on Uttarakhand Flood, http://timesofindia.indiatimes.com/. Retrieved on January 12, 2015

[32] Egemen K. Çetinkaya and James P.G. Sterbenz, Mobile Wireless Networking the University of Kansas EECS 882 Mobility Models in ns-3. http://www.ittc.ku.edu/ jpgs/courses/mwnets/lecturelab-mobile-ns3-display.pdf. Retrieved on January 15, 2015.

\section{Authors}

Dr.S.Sivagurunathan is an Assistant Professor in the Department of Computer Science and Applications, Gandhigram Rural Institute-Deemed University, Gandhigram, Tamilnadu, India. He received his B.Sc degree in Physics from Madurai Kamaraj University in the year 1995 and the M.C.A degree in Computer Applications and M.Phil degree in Computer Science from Madurai Kamaraj University, Madurai in the year 1998 and 2004 respectively. He received his Ph.D degree in Network Security from Anna University in

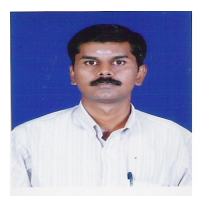
the year 2010. He has seventeen years of experience in teaching. He is a life member of Computer Society of India (CSI). He has more than twenty publications in reputed Journals and Conferences and four publications in as book chapters. His areas of interest are Computer Networks, Mobile Ad hoc Networks, Network Security, Cloud Computing and Internet of Things. (E-Mail:svgrnth@gmail.com)

Mr.K.Prathapchandran is a Research Scholar in the Department of Computer Science and Applications, Gandhigram Rural Institute-Deemed University, Gandhigram, Tamilnadu, India. He received his B.C.A degree in Computer Applications from Madurai Kamaraj University in the year 2005, the M.C.A degree from Gandhigram Rural Institute Deemed University in the year 2008 and the M.Phil degree in Computer Science from Bharathidasan University in the year 2010. He has two years of experience in teaching.

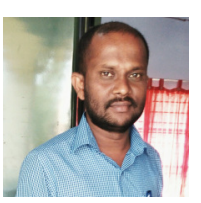
He has fifteen publications in reputed Journals as well as conference proceedings. His areas of interest are Computer Networks, Mobile Ad Hoc Networks, Internet of Things (IoT) and Network Security.

(E-Mail:kprathapchandran@gmail.com) 